\title{
Reductionism in medicine
}

\author{
Pablo Young ${ }^{1 *}$ and Pablo R. Justich ${ }^{2}$ \\ ${ }^{1}$ Servicio de Clínica Médica, Hospital Británico de Buenos Aires, Buenos Aires, Argentina; ${ }^{2}$ Hospital La Vega, Murcia, Spain
}

We have read carefully the work of the Biologist Juan Emilio Sala published in the Boletín Médico del Hospital Infantil de México ${ }^{1}$. We agree with the author that complex thinking and holistic vision are superior to the pure reductionist look. We have found the contribution of both clinical cases as a clarifying mean to convey his idea. The author sets out in the first paragraphs that he intends to generate a debate in the ways of thinking of pediatricians and physicians. To us, he has generated it, so he has fulfilled his purpose. Although there are things which it is difficult to agree on, the debate raised through the argumentation opens the horizon for further improvement.

In general terms, we observe a complete and complex analysis in line with what the topic deserves. We also believe, even from dissimilar ideological perspectives, that the first part of the article, based on very appealing sociological instruments, proposes an almost causal relation between the evolution of Adam Smith's division of labor and the evolution of medicine. It seems to us more as a demonstration of the ontological reductionism that is being questioned in the article than a proof of a broad vision of a multifactorial, dynamic, and transversal phenomenon such as the thinking evolution in medicine. We can share or discuss the effects produced by the bourgeoisie or neoliberalism on the models of attention or in certain partial behavioral imprinting, but the generalization toward the complex thought of our art/science has very limited value. This simplification can lead us to insufficiently well-founded conclusions. Undoubtedly, we agree that the reductionism "excesses" pose a risk, but we believe that these risks are due more to the need for adjustment in certain perspectives than to a social consequence directly related to the different ideological currents, either liberal, Marxist ${ }^{2}$.

Human knowledge is cumulative. At the beginning of time, humans could boast of knowing almost everything. As that knowledge became more complex by the sum of discoveries, their interrelation, and the appearance of countless hypotheses and critiques, each science was no longer a part of a whole and compartmentalization began ${ }^{3}$. We see this phenomenon in law, medicine, physics, biology, political science, and so on. As everything has become more complex, study and research become fragmented, but none of these parts forgets that it is a part of a larger universe that all sciences integrate. What would medicine be if we were all general practitioners and did everything (clinic, neurosurgery, and attended births), and what would happen if the biologists did not specialize? Would everyone know all about all the species addressed?

The author, Juan Emilio Sala, is in favor of the "clichés." He talks about the "Hegemonic" Medical Model ( $\mathrm{MMH}$, for its Spanish acronym) and the professionalization of medicine as if it was a good thing to return to the use of healing herbs and the practices of pre-Columbian medicine. Furthermore, in the medical activity carried out in the large health centers, especially in the United States, he imagines that patients are "jibarized,"

\section{Correspondence:}

*Pablo Young

E-mail: pabloyoung2003@yahoo.com.ar
Date of reception: 19-04-2018

Date of acceptance: 15-05-2018

DOI: 10.24875/BMHIME.M18000046
Available online: 23-11-2018 Bol Med Hosp Infant Mex. 2018;75:227-229

www.bmhim.com 
studied in parts, and fragmented through exaggerated specialization. The author leads us through the $\mathrm{MMH}$, introducing a semantic issue which is at least questionable, not because he does not define and cite it correctly, but because he ends up making an epistemological generalization that, in our view, is unfair and inconsistent. The MMH seems to us as an unfortunately coined and irresponsibly spread term that does not resist even a semantic analysis. This concept, which has been widely misused as a topic of lapidary criticism by many people outside our profession, suggests that the hegemonic medical thought (e.g., the one of the vast majority of physicians) is not humanistic and does not claim the holistic view or the ecological approach to our patients. Moreover, it assumes that a physician is equivalent to a biologist, and this conception is wrong. We believe that it is one of the sequels of evidence-based medicine (EBM) so exploited as a doctrine today.

The author assumes that there is hyperspecialization, as if the specialists, even the most fanatical ones did not know that their part, by its definition, is only a part of a whole. It would be absurd if someone did not know that. However, the author attributes the fragmentation only to the "globalized liberal" system, ignoring that when it exists, it is transversal. The consideration that this phenomenon originates in the "bourgeois" character of Western medicine seems to us a partial, segmental, and excessively reductionist view of this phenomenon, which has in reality more coincidences with knowledge multiplication, its interaction, socialization, and amplification, than with the way in which different societies are related to the means of production.

Juan Emilio Sala says that the specialization process began in the $50 \mathrm{~s}$, but it was not. There were always specialization needs, depending on each specialty. What indeed happened after the Second War was a boom of technology in the service of medicine, and this phenomenon multiplied the need to specialize. It brought its costs, which in general were intended to be transferred to those who consume the benefits. However, everything was a process that did not evolve in jumps, but rather as a sequence of events with often secular tendencies influenced by an infinity of causes (interest, chance, and vocation).

The author says that medical specialization "would lead to the dismemberment of the body to unimaginable extremes," which has never happened in any civilized country, regardless of their prevailing ideology.

To think that the economic model that Adam Smith described has influenced medicine, formatting it, is quite curious; it even seems original. The truth is that the economy was taking its form following what happened in the world, in politics, in international relations, and societies. The evolution of medicine suffered the same process but autonomously ${ }^{4}$.

The author speaks of "the logic inherent of capitalism" as if it was a disqualification, which is a matter of opinion, and we believe that it exceeds the analysis of the central topic.

We hold that, as in other orders of the sciences whether they are exact, natural, or social, there are rational bases or critical realism positions that contribute to the sciences evolution richness. Does the author know any logic other than Aristotelian-Thomism or formal logic?

Sala's severe criticisms of the so-called Vienna Circle are challenging to sustain. Just as with the Frankfurt School, they had their successes and mistakes, but they were carried out by each of those who integrated them. Even supposing that the Vienna Circle was the product of a homogeneous thought is excessive. Many of the thinkers in those conglomerates failed because they were tied to ideologies that do not seem to have had the desired success. What is certain is that, if those who made up that circle could wake up today, they would be amazed at the mere possibility of being taken as exponents of a single thought.

Perhaps, that is why "reductionist" terms are used, which imply nothing in practical terms. The principle "clarity is the philosopher's courtesy" is forgotten. When something is explained, it must be able to be sustained by reality. It is what Karl R. Popper (1902-1994) called "contrastability." The author's statements collide with reality, perhaps for expressing a very strict dogmatism.

When Juan Emilio Sala speaks of "reductionism" and the cartesian method as if they were fundamental errors, he confronts the history of scientific research itself. Civilization has not done so badly with these mechanisms. While the road that remains to be traveled is enormous-no one knows how much or what the final goal is-the author tries to disqualify what has been done simply because it does not fit what he supposes that should be the demands (which have not been discovered by anyone), which seems exaggerated to us. What should be required to the articles is that they illustrate, clarify, not to confuse, especially when there is already enough confusion in many spirits.

Concerning what the author mentioned about his experience with doctors and diagnosis, and extrapolating what Michelangelo said about The Pity, "How can I make a sculpture? Just by removing from the marble block everything that is not necessary ${ }^{5}$." Thus, to reach 
the diagnosis, just as Michelangelo makes a sculpture, certain steps of reasoning are required, which must be trained and be part of the complex thought ${ }^{3,6}$. That thought is exercised during residency, which we believe it should be mandatory and, as such, the only way to obtain the qualification to practice the profession. Moreover, other factors must be taken into account at the time of the medical consultation, such as interruptions (telephones) and the time factor, which is a key for being able to develop the intended complex thought ${ }^{7,8}$.

Concerning the first clinical case mentioned, there is no doubt that the excellent pediatric hepatologist criteria allowed reducing risks and anticipating the diagnosis. However, the succession of reductive processes that allowed reaching the diagnosis should not be forgotten: The baby had been attended by a neonatologist (a subspecialty of pediatrics and at the same time a specialty of medicine) that derived it to a subspecialist in pediatric hepatology. We could ask ourselves, in the absence of these subspecialties referrals (reductionism), if the diagnosis might have been opportunely reached through general medicine.

Finally, we would like to appeal to the second clinical case reported by Sala, when he mentions the damage-at a neurobiological level-that the knowledge of survival statistics produces to the individual. While it is true that the inappropriate use of statistics can cause damage to those who do not master concepts such as dispersion measures and others, it should be recognized that, when interpreted correctly, statistics are very useful for decision-making. The conceptual error is thinking that statistical values are an instrument of direct communication with the patient. As physicians, we should use that instrument within a context and with the knowledge that it allows giving real meaning to a cold number. Here is where the EBM unequivocally fails: it adapts the subject to the number and does not use that number at the subject's service, taking into account his singularities. We should use statistics for our understanding and translate the message generated by those values to our patients, using understandable and useful terms as long as they can assimilate them.

Medicine and public health evolution-along with their specialties progress-provide an analytical dissociation resulting in a very effective tool, which not only does not "jibarize" knowledge but also it enhances the comprehensive understanding of the patient, adding perspectives in all the possible layers, and bringing us closer to offering a better health care to our patients.

\section{References}

1. Sala JE. La jibarización del logos: cómo el reduccionismo médico puede matar. Bol Med Hosp Infant Mex. 2017;74:154-63.

2. Greene JA, Loscalzo J. Putting the patient back together-Social Medicine, Network Medicine, and the Limits of Reductionism. N Engl J Med. 2017;377:2493-9.

3. De Vito EL. La medicina "al borde del caos". Vida, entropía y complejidad. Medicina (B Aires). 2016;76:45-54.

4. Justich PR. ¿Medicina basada en el mercado o medicina basada en el paciente? Arch Argent Pediatr. 2015;113:146-53.

5. García C. El mármol que sobra. 2018 Feb 18. En: Blog Mi médico de cabecera [Internet]. Available at: https://mimedicodecabecera.blogspot. com.ar/2018/02/el-marmol-que-sobra.html.

6. D’Negri CE, De Vito EL. Introducción al razonamiento aproximado: lógica difusa. Rev Arg Med Resp. 2006;4:126-36.

7. Losasso $A$, Rubinstein $E$. El diagnóstico va construyéndose con el tiempo. Rev Hosp Ital B Aires. 2006;26:103-6.

8. Justich ZP. 6 minutos. Arch Argent Pediatr. 2018;116:e70-4. 